\title{
Short chain U(600) di-urea cross-linked poly(oxyethylene)/siloxane ormolytes doped with lanthanum triflate salt
}

\author{
${ }^{\mathrm{a}}$ S.M. Gomes Correia, ${ }^{\mathrm{a}}$ V. de Zea Bermudez *, M.M. Silva ${ }^{\mathrm{b}}$, S. Barros ${ }^{\mathrm{b}}$, R.A. Sá Ferreira ${ }^{\mathrm{c}}$, \\ L.D. Carlos $^{\mathrm{c}}$, M.J. Smith
}

àDepartamento de Química, Universidade de Traás-os-Montes e Alto Douro, Quinta de Prados, Apartado 1013, 5000-911 Vila Real, Portugal, 'bepartamento de Química, Universidade do Minho, Gualtar, 4710-057 Braga, Portugal, ' Departamento de Física, Universidade de Aveiro, 3810-193 Aveiro, Portugal.

\begin{abstract}
Promising $\mathrm{La}^{3+}$-doped electrolytes based on a hybrid poly(oxyethylene)/siliceous host matrix, U(600), have been produced. The organic and inorganic components of the hybrid structure are covalently bonded through urea linkages. The low molecular weight of the polyether $\mathrm{U}(600)$ segments is thought to be responsible for the total amorphous character and relatively high room temperature conductivity $\left(1 \times 10^{-4} \mathrm{Scm}^{-1}\right)$ of these ormolytes.
\end{abstract}

\section{Conclusion}

Totally amosphous sol-gel derived ormolytes with a wide range of salt concentration have been characterized. The use of the hybrid U(600) di-ureasil host structure instead of poly(oxyethylene) resulted in materials with improved mechanical and thermal charateristics. In addition, a remarkable enhancement of ionic conductivity levels at temperatures lower than $60^{\circ}$ resulted. The composition of the electrolyte with optimum conductivity was identified as about $\mathrm{n}$ $=40$.

The formation of a network by bonding relatively low molecular weight chains to a siliceous micro-domain gave rise to a completely amorphous material which is flexible, slightly hygroscopic network with good thermal stability. 